\title{
MicroRNA-539 inhibits colorectal cancer progression by directly targeting SOX4
}

\author{
JIAN ZHAO, JIAN XU and RUI ZHANG \\ Department of Colorectal Surgery, Cancer Hospital of China Medical University, \\ Liaoning Cancer Hospital and Institute, Shenyang, Liaoning 110042, P.R. China
}

Received February 23, 2017; Accepted October 26, 2017

DOI: $10.3892 / \mathrm{ol} .2018 .8892$

\begin{abstract}
Colorectal cancer (CRC) is the third most prevalent cancer and the fourth most common cause of cancer-associated mortality in males and females globally. Aberrant expression of microRNA-539 (miR-539) has been reported in multiple types of cancer. However, miR-539 expression, function and underlying mechanisms have not been clearly elucidated in CRC. In the present study, miR-539 expression was detected by reverse transcription-quantitative polymerase chain reaction (RT-qPCR) in CRC tissues and cell lines. The effects of miR-539 on CRC cells were further examined in in vitro studies. In addition, the direct targets of miR-539 in CRC were investigated using bioinformatics, luciferase reporter assays, RT-qPCR and western blotting. miR-539 was revealed to be significantly downregulated in CRC cell lines and tissues. Decreased miR-539 expression was associated with lymph node metastasis and tumor-node-metastasis stage in patients with CRC. Functional assays revealed that the rescue of miR-539 expression attenuated CRC cell proliferation and invasion in vitro. Additionally, SRY-box 4 (SOX4) was validated as a direct target gene of miR-539 in CRC. Furthermore, SOX4 was revealed to be upregulated in CRC tissues at the mRNA and protein level. A significant negative correlation between miR-539 and SOX4 mRNA expression levels was observed in CRC tissues. Furthermore, upregulation of SOX4 partially restored the tumor suppressive effects of miR-539 on CRC cell proliferation and invasion. Taken together, this suggests that miR-539 may serve tumor-suppressive functions in CRC during the process of malignant transformation, by directly targeting SOX4. miR-539/SOX4-based targeted therapy may represent a potential novel treatment for patients with CRC.
\end{abstract}

Correspondence to: Professor Rui Zhang, Department of Colorectal Surgery, Cancer Hospital of China Medical University, Liaoning Cancer Hospital and Institute, 44 Xiaoheyan Road, Shenyang, Liaoning 110042, P.R. China

E-mail: ruizhang_cmu@163.com

Key words: colorectal cancer, microRNA-539, SRY-box 4, proliferation, invasion

\section{Introduction}

Colorectal cancer (CRC), which includes colon cancer and rectal cancer, is the third most prevalent cancer and the fourth most common cause of cancer-associated mortality in males and females worldwide in 2016, with $>1$ million cases diagnosed and 600,000 deaths recorded each year $(1,2)$. Multiple risk factors for CRC have been identified, including age, being of the male sex, consumption of alcohol and red meat, obesity, insulin resistance and metabolic syndrome (3). At present, the standard treatment for CRC is surgical resection followed by chemotherapy and radiotherapy (4). Despite the advances that have been achieved in the diagnosis and therapy of CRC, however, the prognosis of patients with CRC remains poor (5). Overall, $30-50 \%$ of patients with CRC develop local tumor recurrence or distant metastasis, even following curative resection of the primary lesion $(6,7)$. Therefore, it is crucial to fully understand the underlying mechanisms involved in CRC development and progression, and identify novel, efficient and specific therapeutic targets for the treatment of patients with CRC.

MicroRNAs (miRNAs/miRs) are a group of evolutionarily conserved, non-coding, short RNA molecules found in plants, animals and certain viruses (8). miRNAs serve an important function in the regulation of gene expression by interacting with complementary sites in the 3'-untranslated regions (3'-UTRs) of target mRNAs, inducing translational repression or mRNA cleavage (9). Multiple studies have reported that miRNAs regulate a number of physiological and pathological processes, which include cell proliferation, the cell cycle, differentiation, apoptosis, metastasis, angiogenesis and metabolism (10-12). miRNAs are involved in tumorigenesis and cancer development, with $>50 \%$ of miRNAs located at cancer-associated genomic regions $(13,14)$. Aberrant expression of multiple miRNAs has been observed in various types of human cancer, including CRC (15-17). Furthermore, these abnormally expressed miRNAs may act as tumor suppressors or oncogenes in different types of human cancer depending on whether they specifically target oncogenes or tumor suppressor genes $(18,19)$. Thus, the targeting of miRNAs may result in novel anti-cancer therapies, as a result of the close associations between miRNAs and carcinogenesis.

miR-539 has been reported to be aberrantly expressed in several types of cancer including prostate cancer (20), 
nasopharyngeal carcinoma (21) and osteosarcoma (22). However, the expression levels, biological functions and underlying mechanisms of miR-539 in CRC remain unclear. Therefore, the aim of the present study was to detect miR-539 expression and to investigate the biological functions of miR-539 in CRC, as well as the potential mechanisms underlying these functions.

\section{Materials and methods}

Clinical samples. The present study was approved by the Ethics Committee of Liaoning Cancer Hospital and Institute (Shenyang, China), and written informed consent was obtained from all patients enrolled in the study. A total of 49 pairs of $\mathrm{CRC}$ tissues and corresponding normal adjacent tissues were collected from patients with CRC who underwent surgical resection at the Liaoning Cancer Hospital and Institute between June 2012 and October 2015. All these tissues were derived from initial surgery with neither preoperative chemotherapy or radiotherapy. Tissue samples were promptly frozen in liquid nitrogen at the time of surgery and stored at $-80^{\circ} \mathrm{C}$ until further use. Clinicopathological features of the patients are listed in Table I.

Cell lines and transfection. A total of five human CRC cell lines (LoVo, HCT116, HT29, SW480 and SW620) and the normal human colon epithelium cell line FHC were purchased from the American Type Culture Collection (Manassas, VA, USA). Cells were cultured in Dulbecco's modified Eagle's medium (DMEM; Gibco; Thermo Fisher Scientific, Inc., Waltham, MA, USA) containing 10\% fetal bovine serum (FBS; Gibco; Thermo Fisher Scientific, Inc.), $100 \mathrm{U} / \mathrm{ml}$ penicillin and $100 \mathrm{mg} / \mathrm{ml}$ streptomycin. All cell lines were maintained at $37^{\circ} \mathrm{C}$ in a humidified atmosphere of $5 \% \mathrm{CO}_{2}$.

miR-539 mimics and corresponding negative control miRNA (miR-NC) were acquired from Shanghai GenePharma Co., Ltd. (Shanghai, China). The miR-539 mimics sequence was 5'-GGAGAAAUUAUCCUUGGUGUUGU-3' and the miR-NC sequence was 5'-UUCUCCGAACGUGUCACG UTT-3'. pcDNA3.1-SRY-box 4 (SOX4) plasmids and empty vector pcDNA3.1 plasmids were synthesized by Guangzhou RiboBio Co., Ltd (Guangzhou, China). For transfection, cells were seeded into 6-well plates in DMEM medium containing $10 \%$ FBS at $60-70 \%$ confluence. Following incubation overnight at $37^{\circ} \mathrm{C}$ with $5 \% \mathrm{CO}_{2}$, cells were transfected with miRNA mimics (100 pmol) or plasmids (4 g) using Lipofectamine 2000 (Invitrogen; Thermo Fisher Scientific, Inc.), following the manufacturer's protocol. The culture medium was replaced with fresh DMEM supplemented with 10\% FBS $8 \mathrm{~h}$ after transfection.

Reverse transcription-quantitative polymerase chain reaction $(R T-q P C R)$. Total RNA was isolated from the cell lines and tissue samples using TRIzol reagent (Invitrogen; Thermo Fisher Scientific, Inc.), in accordance with the manufacturer's protocol. The concentration of total RNA was examined using a NanoDrop 2000 spectrophotometer (Thermo Fisher Scientific, Inc.). For analysis of miR-539 expression, cDNA was synthesized using the TaqMan MicroRNA Reverse Transcription kit (Applied Biosystems; Thermo Fisher Scientific, Inc.) according to the manufacturer's protocol.
qPCR was performed using a TaqMan MicroRNA PCR kit (Applied Biosystems; Thermo Fisher Scientific, Inc.) on an ABI Prism 7500 Sequence Detection System (Applied Biosystems; Thermo Fisher Scientific, Inc.). The cycling conditions for qPCR were as follows: $50^{\circ} \mathrm{C}$ for $2 \mathrm{~min}, 95^{\circ} \mathrm{C}$ for $10 \mathrm{~min}$; 40 cycles of denaturation at $95^{\circ} \mathrm{C}$ for $15 \mathrm{sec}$; and annealing/extension at $60^{\circ} \mathrm{C}$ for $60 \mathrm{sec}$. To quantify SOX4 mRNA, reverse transcription was conducted using a PrimeScript RT Reagent kit (Takara Biotechnology Co., Ltd., Dalian, China) according to the manufacturer's protocol, and qPCR was performed using SYBR Premix Ex Taq ${ }^{\mathrm{TM}}$ (Takara Biotechnology Co., Ltd., Dalian, China). The cycling conditions for qPCR were as follows: $5 \mathrm{~min}$ at $95^{\circ} \mathrm{C}$, followed by 40 cycles of $95^{\circ} \mathrm{C}$ for $30 \mathrm{sec}$ and $65^{\circ} \mathrm{C}$ for $45 \mathrm{sec}$.

U6 and GAPDH served as internal controls for the detection of miR-539 and SOX4 mRNA, respectively. The primers were designed as follows: miR-539, 5'-GAAGAGGCTAAC GTGAGGTTG-3' (forward) and 5'-CACCATGACCAAGCC ACGTAG-3' (reverse); U6, 5'-GCTTCGGCAGCACATATA CTAAAAT-3' (forward) and 5'-CGCTTCACGAATTTGCGT GTCAT-3' (reverse); SOX4, 5'-CTTGACATGATTAGCTGG CATGATT-3' (forward) and 5'-CCTGTGCAATATGCCGTG TAGA-3' (reverse); and GAPDH, 5'-CCAAAATCAGATGGG GCAATGCTGG-3' (forward) and 5'-TGATGGCATGGACTG TGGTCATTCA-3' (reverse). The $2^{-\Delta \Delta C q}$ method was used for relative quantification (23).

MTT assay. Cell proliferation was determined using MTT assays. Transfected cells were harvested, resuspended in DMEM medium containing 10\% FBS and seeded in 96-well plates at a density of $3 \times 10^{3}$ cells/well, and cultured for $0,24,48$, and $72 \mathrm{~h}$. At these specified times, MTT assays were performed. Briefly, $20 \mu 1$ MTT solution (5 mg/ml; Sigma-Aldrich; Merck KGaA, Darmstadt, Germany) was added into each well and incubated at $37^{\circ} \mathrm{C}$ with $5 \% \mathrm{CO}_{2}$ for additional $4 \mathrm{~h}$. The culture medium was then removed and dimethyl sulfoxide (Sigma-Aldrich; Merck KGaA) was used to dissolve the formazan crystals at $37^{\circ} \mathrm{C}$ for $10 \mathrm{~min}$. Finally, the absorbance at $490 \mathrm{~nm}$ was detected using a microplate reader (iMark ${ }^{\mathrm{TM}}$; Bio-Rad Laboratories, Inc., Hercules, CA, USA). All experiments were performed in triplicate and repeated at least three times.

Cell invasion assay. Cell invasion assays were performed using Transwell chambers $(8 \mathrm{~mm}$ pores; Costar, Corning Incorporated, NY USA) coated with Matrigel solution (40 $\mu 1$ per chamber; Matrigel: FBS-free medium ratio 1:10; BD Biosciences, San Jose, CA, USA). Following transfection for $48 \mathrm{~h}, 5 \times 10^{4}$ cells cultured with FBS-free DMEM medium were placed into the upper chamber, and the lower chamber was filled with $500 \mu \mathrm{l}$ DMEM with $20 \%$ FBS. After $48 \mathrm{~h}$ of incubation at $37^{\circ} \mathrm{C}$, cells on the upper surface of the membrane were carefully removed with cotton swab. Cells that invaded through the membrane surface were fixed in 100\% methanol at room temperature for $15 \mathrm{~min}$, stained with $0.1 \%$ crystal violet at room temperature for $15 \mathrm{~min}$, and photographed under a light microscope (Olympus Corporation, Tokyo, Japan) at x200 magnification in five randomized fields.

Bioinformatic analysis and luciferase reporter assay. Target genes of miR-539 were searched using TargetScan (24) 
Table I. Associations between miR-539 expression and clinicopathological characteristics of patients with colorectal cancer.

\begin{tabular}{|c|c|c|c|c|}
\hline \multirow{2}{*}{$\begin{array}{l}\text { Clinicopathological } \\
\text { features }\end{array}$} & \multirow[b]{2}{*}{ Cases } & \multicolumn{2}{|c|}{$\begin{array}{c}\text { miR-539 } \\
\text { expression }\end{array}$} & \multirow[b]{2}{*}{ P-value } \\
\hline & & Low & High & \\
\hline Sex & & & & 0.320 \\
\hline Male & 30 & 17 & 13 & \\
\hline Female & 19 & 8 & 11 & \\
\hline Age, years & & & & 0.628 \\
\hline$<60$ & 18 & 10 & 8 & \\
\hline$\geq 60$ & 31 & 15 & 16 & \\
\hline Tumor location & & & & 0.458 \\
\hline Colon & 21 & 12 & 9 & \\
\hline Rectum & 28 & 13 & 15 & \\
\hline Tumor size, cm & & & & 0.316 \\
\hline$<5$ & 24 & 14 & 10 & \\
\hline$\geq 5$ & 25 & 11 & 14 & \\
\hline Differentiation & & & & 0.117 \\
\hline Well and moderate & 26 & 16 & 10 & \\
\hline Poor & 23 & 9 & 14 & \\
\hline $\begin{array}{l}\text { Lymph node } \\
\text { metastasis }\end{array}$ & & & & 0.015 \\
\hline No & 26 & 9 & 17 & \\
\hline Yes & 23 & 16 & 7 & \\
\hline TNM stage & & & & 0.007 \\
\hline I-II & 23 & 7 & 16 & \\
\hline III-IV & 26 & 18 & 8 & \\
\hline
\end{tabular}

miR-539, microRNA-539; TNM, tumor-node-metastasis.

(http//www.targetscan.org) and miRBase (14,25-27) (http://www.mirbase.org/).

For the luciferase reporter assay, pMIR-SOX4-3'-UTR-wild type (WT) and pMIR-SOX4-3'-UTR-mutant (MUT) were synthesized by Shanghai GenePharma Co., Ltd. Cells were seeded into 24 well plates at 60-70\% confluence, and transfected with miR-539 mimics or miR-NC with pMIR-SOX4-3'-UTR-WT or pMIR-SOX4-3'-UTR-MUT using Lipofectamine 2000, according to the manufacturer's protocol. The activity of Renilla luciferase and firefly luciferase was determined $48 \mathrm{~h}$ after transfection using a Dual-Luciferase Reporter Assay system (Promega Corporation, Madison, WI, USA), according to the manufacturer's protocol. The relative luciferase activity was normalized to Renilla luciferase activity.

Western blot. Protein was extracted from tissues and cells using a Total Protein Extraction kit (Nanjing KeyGen Biotech Co., Ltd., Nanjing, China) supplemented with a protease inhibitor cocktail (Sigma-Aldrich; Merck KGaA), according to the manufacturer's protocol. Protein concentration was detected using a BCA kit (Beyotime Institute of Biotechnology, Haimen, China). Equal amounts of protein $(30 \mu \mathrm{g})$ were resolved on $10 \%$ sodium dodecyl sulfate-polyacrylamide gels and transferred to polyvinylidene difluoride membranes (EMD Millipore, Billerica, MA, USA). Subsequently, the membranes were blocked at room temperature with 5\% non-fat milk in TBS/0.1\% Tween (TBST) for $1 \mathrm{~h}$, and incubated with the following primary antibodies overnight at $4^{\circ} \mathrm{C}$ : Mouse anti-human monoclonal SOX4 (1:1,000; cat. No. sc-130633; Santa Cruz Biotechnology, Inc., Dallas, TX, USA) and mouse anti-human monoclonal GAPDH (1:1,000; cat. no. sc-51907; Santa Cruz Biotechnology, Inc.). Following three washes with TBST, the membranes were incubated with a goat-anti-mouse horseradish peroxidase-conjugated secondary antibody (1:3,000; cat. no. sc-2005; Santa Cruz Biotechnology, Inc.) at room temperature for $1 \mathrm{~h}$. Protein bands were developed using an enhanced chemiluminescent reagent (GE Healthcare Life Sciences, Little Chalfont, UK) and analyzed with Image Lab software (version 3.0; Bio-Rad Laboratories, Inc.). GAPDH was used as a loading control.

Statistical analysis. Each assay was repeated three times, and data were expressed as the mean \pm standard deviation. All statistical analyses were performed using Spearman's correlation test, paired Student's t-test or one-way analysis of variance (ANOVA) with SPSS 18.0 software (SPSS, Inc., Chicago, IL, USA). Student-Newman-Keuls test was used as a post hoc test following ANOVA. The association between miR-539 expression and the clinicopathological factors in CRC was analyzed by the $\chi^{2}$ test. $\mathrm{P}<0.05$ was considered to indicate a statistically significant difference.

\section{Results}

miR-539 expression is downregulated in CRC tissues and cell lines. To investigate the expression patterns of miR-539 in CRC, miR-539 expression was examined in 49 pairs of CRC tissues and corresponding normal adjacent tissues by RT-qPCR. The results demonstrated that, compared with normal adjacent tissues, miR-539 was significantly downregulated in $\mathrm{CRC}$ tissues (Fig. $1 \mathrm{~A} ; \mathrm{P}<0.05$ ). To analyze the associations between miR-539 expression and the clinicopathological characteristics of patients with $\mathrm{CRC}$, the median miR-539 expression level (0.629) was regarded as the cut-off to divide all patients into either the miR-539 low-expression group ( $n=25)$ or the miR-539 high-expression group $(n=24)$. As presented in Table I, a low expression level of miR-539 was associated with lymph node metastasis $(\mathrm{P}=0.015)$ and tumor-node-metastasis (TNM) stage (28) $(\mathrm{P}=0.007)$. However, no significant associations were observed between miR-539 levels or any other clinicopathological factor, which included sex $(\mathrm{P}=0.320)$, age $(\mathrm{P}=0.628)$, tumor location $(\mathrm{P}=0.458)$, tumor size $(\mathrm{P}=0.316)$ or differentiation $(\mathrm{P}=0.117)$.

Subsequently, miR-539 expression was measured in five CRC cell lines and a normal human colon epithelium cell line by RT-qPCR. As presented in Fig. 1B, the expression levels of miR-539 were decreased in all five $\mathrm{CRC}$ cell lines relative to FHC cells $(\mathrm{P}<0.05)$. CT116 and SW480 cell lines, which expressed relatively lower miR-539 expression level, were selected for further experiments. These results suggested that miR-539 may be involved in CRC initiation and progression.

miR-539 inhibits CRC cell proliferation and invasion in vitro. To observe the potential effects of miR-539 on CRC 
A

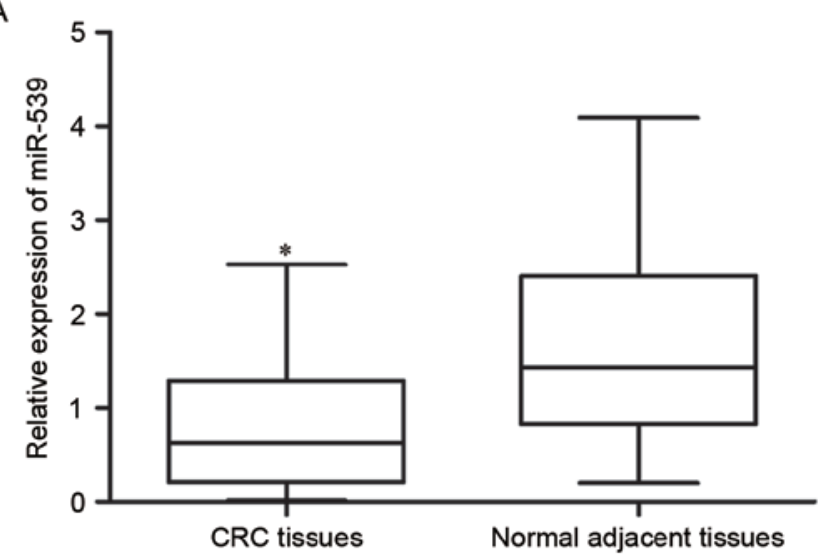

B

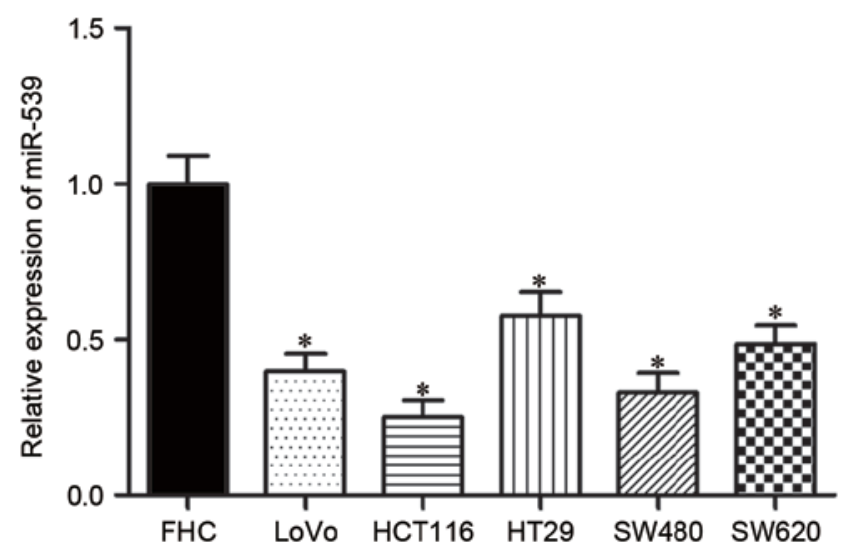

Figure 1. miR-539 was downregulated in CRC tissues and cell lines. (A) The expression of miR-539 was detected in 49 pairs of CRC tissues and corresponding normal adjacent tissues by reverse transcription-quantitative polymerase chain reaction. " $\mathrm{P}<0.05$ vs. normal adjacent tissues. (B) Relative expression levels of miR-539 in five CRC cell lines (LoVo, HCT116, HT29, SW480 and SW620) and the normal human colon epithelium cell line FHC. ${ }^{\text {*P }}<0.05$ vs. the FHC. miR-539, microRNA-539; CRC, colorectal cancer.

cells, miR-539 mimics or miR-NC were transfected into HCT116 and SW480 cells. Following transfection, RT-qPCR confirmed that miR-539 expression was increased in HCT116 and SW480 cells transfected with miR-539 mimics compared with those transfected with miR-NC (Fig. $2 \mathrm{~A}, \mathrm{P}<0.05$ ). MTT assays were utilized to assess whether miR-539 contributed to the suppression of CRC cell proliferation. Transfection of miR-539 mimics was revealed to significantly inhibit the proliferation of HCT116 and SW480 cells at $72 \mathrm{~h}$ compared with those transfected with miR-NC (Fig. 2B; P<0.05). Cell invasion assays were performed to determine the effect of miR-539 on the invasiveness of CRC cells. Invasiveness was significantly suppressed in HCT116 and SW480 cells transfected with miR-539 mimics compared with miR-NC (Fig. 2C). Collectively, these results indicated a potential tumor-suppressive function of miR-539 in CRC proliferation and invasion.

Validation of SOX4 as a direct target of miR-539 in CRC. To reveal the mechanism by which miR-539 affects the biological functions of CRC cells, the potential target genes of miR-539 were explored using bioinformatics. Among these putative targets, SOX4 was selected for

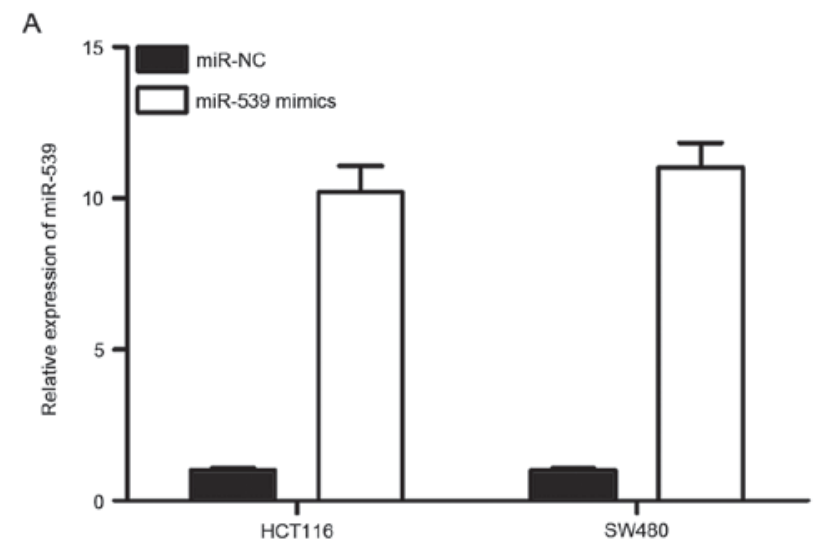

B
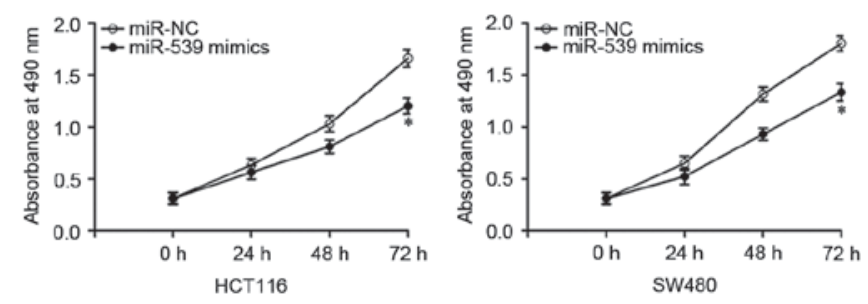

C

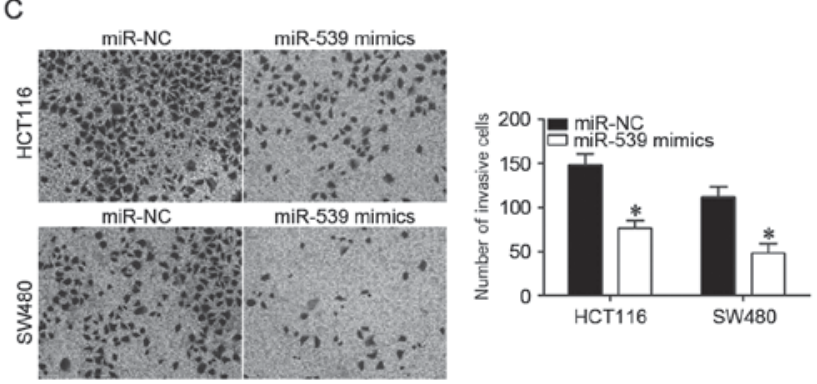

Figure 2. miR-539 overexpression inhibited HCT116 and SW480 cell proliferation and invasion. (A) miR-539 expression in HCT116 and SW480 cells was assessed by reverse transcription-quantitative polymerase chain reaction analysis following transfection with miR-539 mimics. (B) MTT assays revealed that miR-539 mimic transfection significantly suppressed the proliferation of HCT116 and SW480 cells compared with the miR-NC transfected cells. (C) Invasion was assessed in HCT116 and SW480 cells using Transwell invasion assays (x200 magnification). ${ }^{*} \mathrm{P}<0.05$ vs. miR-NC. miR-539, microRNA-539; NC, negative control.

further examination (Fig. 3A), as it is upregulated in CRC and is involved into CRC progression $(29,30)$. A luciferase reporter assay was performed to determine whether miR-539 directly binds to the 3'-UTR of SOX4. HCT116 and SW480 cells were transfected with pMIR-SOX4-3'-UTR-WT or pMIR-SOX4-3'-UTR-MUT, along with miR-539 mimics or miR-NC. As presented in Fig. 3B, the luciferase activity of the reporter containing WT SOX4 3'-UTR was significantly decreased following co-transfection with miR-539 mimics compared with miR-NC $(\mathrm{P}<0.05)$. However, there was no change in luciferase activity of the reporter containing the mutant binding site. Furthermore, RT-qPCR and western blotting were performed to measure the expression of SOX4 in HCT116 and SW480 cells. As predicted, ectopic expression of miR-539 decreased the mRNA and protein levels of SOX4 in HCT116 and SW480 cells compared with miR-NC (Fig. $3 \mathrm{C}$ and $\mathrm{D} ; \mathrm{P}<0.05$ ). Thus, SOX4 was demonstrated to be a direct target of miR-539 in CRC. 


$\begin{array}{lll}\text { SOX4-3'-UTR-WT } & 5 & \text {...AAAACGUUUGAUUAUUUUCUCAG... } \\ \text { hsa-miR-539 } & 33^{\prime} & \text { UGUGUGGUUCCUAUUAAAGAGG } \\ \text { SOX4-3'-UTR-mut } & 5 & \text {...AAAACGUUUGAUUAUAAAGAGAG... }\end{array}$

B

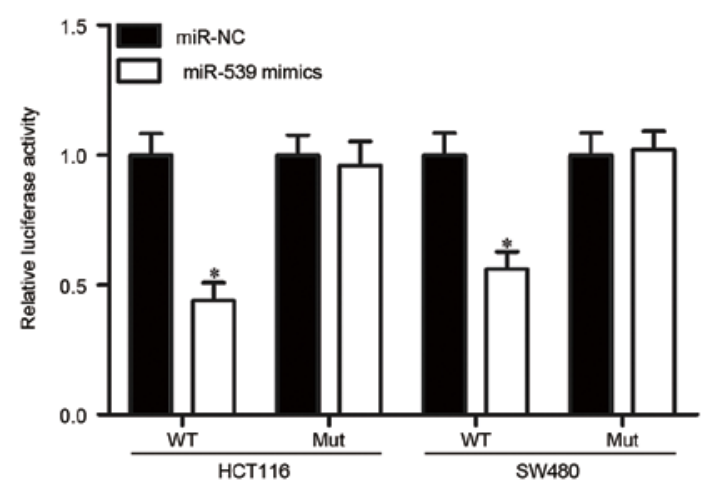

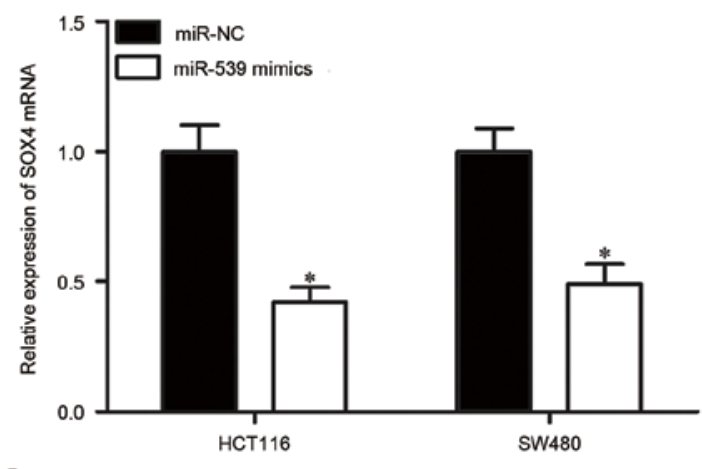

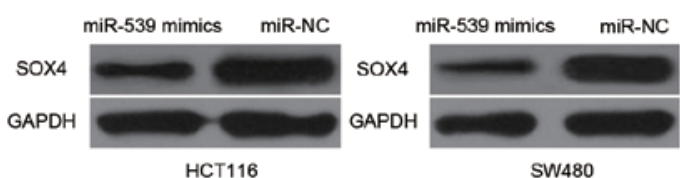

Figure 3. miR-539 directly targets SOX4 in colorectal cancer. (A) The predicted target sequence of miR-539 in the 3'-UTR of the SOX4 gene, and the positions of mutated nucleotides in the 3'-UTR of miR-539. (B) Luciferase reporter assays were performed in HCT116 and SW480 cells co-transfected with miR-539 mimics or miR-NC, and pMIR-SOX4-3'-UTR-WT or pMIR-SOX4-3'-UTR-MUT. (C) SOX4 mRNA levels were detected in HCT116 and SW480 cells in the presence of miR-539 mimics or miR-NC. (D) Western blot analysis of SOX4 protein expression in HCT116 and SW480 cells following transfection with miR-539 mimics or miR-NC. "P<0.05 vs. miR-NC. SOX4, SRY-box 4; UTR, untranslated region; miR-539, microRNA-539; NC, negative control; WT, wild type; MUT, mutant.

miR-539 is inversely correlated with SOX4 expression in $C R C$ tissues. To further investigate the relationship between miR-539 and SOX4, SOX4 mRNA and protein expression in were measured in CRC tissues and corresponding normal adjacent tissues. The results revealed that SOX4 mRNA and protein were upregulated in $\mathrm{CRC}$ tissues compared with the corresponding normal adjacent tissues (Fig. 4A and B; $\mathrm{P}<0.05$ ). Spearman's correlation analysis further revealed that miR-539 expression levels were negatively correlated with SOX4 mRNA expression levels in CRC tissues (Fig. 4C; $r=-0.6698$, $\mathrm{P}<0.001)$. These results suggested that the downregulation of miR-539 may result in the upregulation of SOX4 in CRC.

Upregulation of SOX4 reverses the tumor-suppressive effects of miR-539 in CRC cells. To examine whether the downregulation of SOX4 mediates the tumor suppressive functions of miR-539 in CRC cells, rescue experiments were performed. HCT116 and SW480 cells were transfected with pcDNA3.1-SOX4 to increase its expression (Fig. 5A; $\mathrm{P}<0.05$ ). In addition, further exploration with MTT and Transwell invasion assays indicated that upregulation of SOX4 could rescue the suppressive effects on $\mathrm{CRC}$ cell proliferation (Fig. 5B; $\mathrm{P}<0.05$ ) and invasion (Fig. 5C; $\mathrm{P}<0.05$ ) induced by miR-539 overexpression. Collectively, these results suggested that miR-539 inhibits CRC cell invasion and proliferation by negatively modulating SOX4 expression.

\section{Discussion}

Tumor progression in CRC is a multi-step process that involves alterations at the genetic and epigenetic level (31-33). Accumulated evidence has led to the view that miRNAs serve important functions in cancer formation and through the regulation of tumor cell proliferation, cycle, apoptosis, metastasis and angiogenesis (34-36). Therefore, miRNAs may be potential therapeutic targets for miRNA-based diagnosis, prognosis and therapy. The present study used RT-qPCR to demonstrate that miR-539 expression was significantly decreased in CRC tissues and cell lines. In addition, low expression of miR-539 was significantly associated with tumor progression in patients with CRC. Functional experiments were used to demonstrate that miR-539 upregulation suppressed CRC cell proliferation and invasion. Furthermore, SOX4 was identified as a direct target gene of miR-539 in CRC. In summary, these results suggested that miR-539 may be used to develop novel strategies against $\mathrm{CRC}$ growth and metastasis in the future.

Abnormal expression of miR-539 has been reported to in multiple types of human cancer. For example, a previous study demonstrated that miR-539 was downregulated in an osteosarcoma cell line compared with an osteoblast cell line (37). Mirghasemi et al (38) reported that miR-539 expression levels are relatively low in osteosarcoma tissues, and low expression of miR-539 was associated with TNM stage, metastasis and recurrence. In addition, Kaplan-Meier survival analysis and log-rank tests demonstrated that reduced miR-539 expression was associated with low overall survival in patients with osteosarcoma, and miR-539 was revealed to be an independent prognostic marker of overall survival in patients with osteosarcoma (38). Gu et al (39) reported that miR-539 expression is decreased in thyroid cancer tissues and cell lines. In addition, consistent with these results, low expression levels of miR-539 was observed in nasopharyngeal carcinoma (21) and prostate cancer (20). The high frequency of miR-539 downregulation in these types of human cancer suggested that miR-539 may be a novel marker for the diagnosis and prognosis of specific cancers.

Abnormal expression of miR-539 serves an important function in the initiation and progression of several types of tumor. For instance, upregulation of miR-539 decreases cell migration and invasion in thyroid cancer (39). Another previous study 


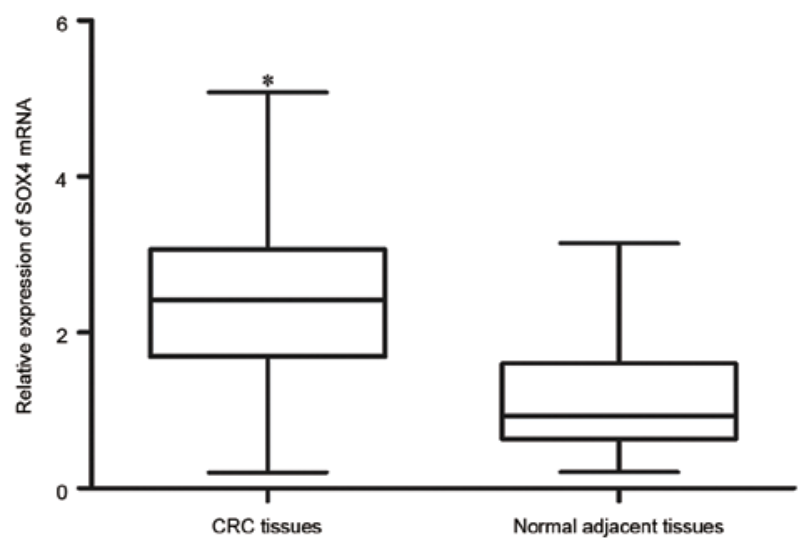

B

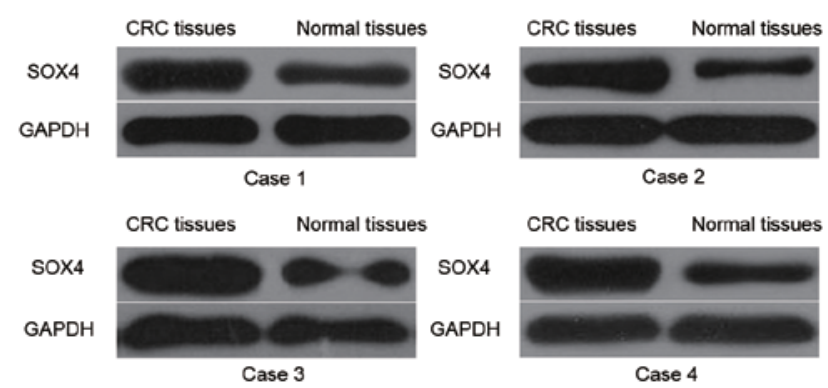

C

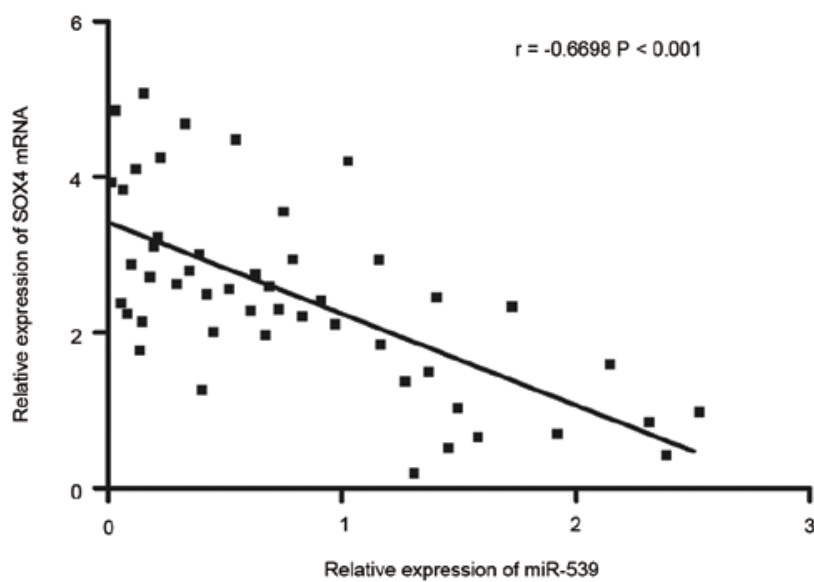

Figure 4. SOX4 was upregulated in CRC tissues and was negatively correlated with miR-539 expression levels. (A) Expression of SOX4 mRNA was assessed in 49 pairs of CRC tissues and corresponding normal adjacent tissues. ${ }^{*} \mathrm{P}<0.05$ vs. normal adjacent tissues. (B) SOX4 protein expression was determined in CRC tissues and normal adjacent tissues by western blotting. (C) There was a significant negative correlation between miR-539 and SOX4 mRNA expression levels in CRC tissues. SOX4, SRY-box 4; CRC, colorectal cancer; miR-539, microRNA-539.

demonstrated that miR-539 serves tumor suppressive functions in the growth and metastasis of osteosarcoma (22). Lv et al (21) reported that enforced expression of miR-539 suppresses the growth of nasopharyngeal carcinoma cells in vitro and in vivo. Meanwhile, Zhang et al (20) demonstrated that restoration of miR-539 expression in prostate cancer represses cell proliferation, migration and invasion in vitro, and decreases tumor growth and metastasis in vivo. These results suggest that miR-539 may serve an important function in these types of cancer, and it may be a potential target for the treatment of specific cancers.
A
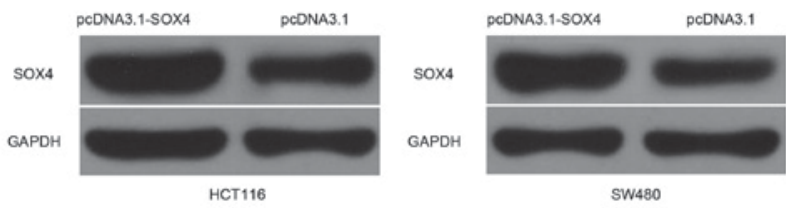

B
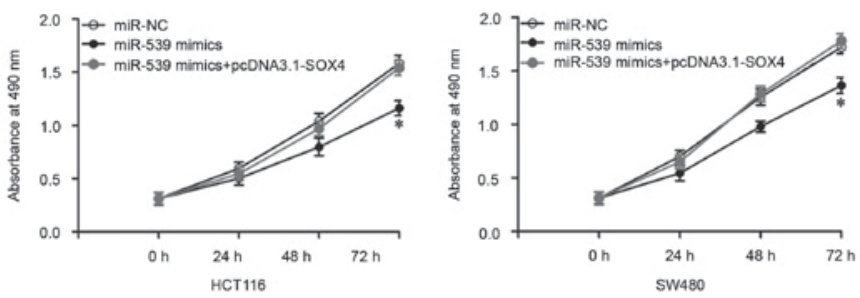

C
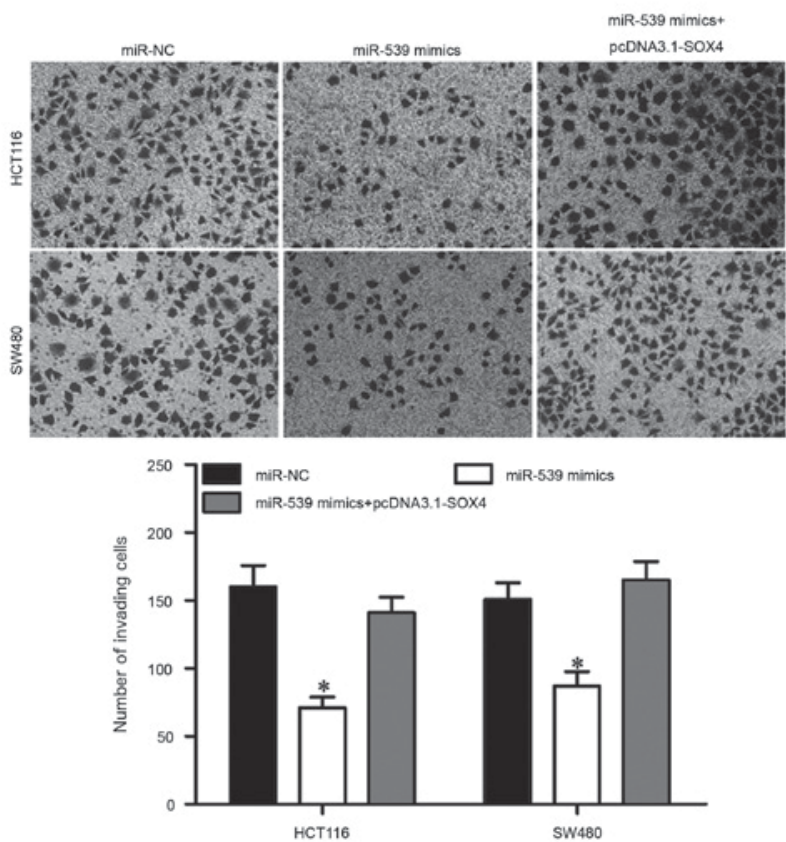

Figure 5. SOX4 rescued the inhibitory effects of miR-539 mimics on HCT116 and SW480 cell proliferation and invasion. (A) Western blot analysis of SOX4 protein expression in HCT116 and SW480 cells transfected with pcDNA3.1-SOX4 or pcDNA3.1. (B) Cell proliferation was assessed by MTT assay. (C) Invasion was assessed by Transwell assay (x200 magnification). ${ }^{*} \mathrm{P}<0.05$ vs. miR-NC and miR-539 mimics+pcDNA3.1-SOX4. SOX4, SRY-box 4; miR-539, microRNA-539; NC, negative control.

Since the potential molecular mechanism underlying the tumor-suppressive effects of miR-539 in CRC remains to be elucidated, the present study aimed to explore this mechanism. To date, few genes have been validated as direct targets of miR-539, including sperm associated antigen 5 in prostate cancer (20), cyclin dependent kinase 4 in nasopharyngeal carcinoma (21), matrix metalloproteinase 8 in osteosarcoma (22) and caspase recruitment domain family member 11 in thyroid cancer (39). In the present study, SOX4 was validated as a novel direct and functional target of miR-539 in CRC. First, bioinformatics predicated SOX4 as a potential target of miR-539. Secondly, luciferase reporter assays demonstrated that miR-539 directly targeted the 3'-UTR of SOX4. Thirdly, overexpression of miR-539 suppressed SOX4 mRNA and protein expression in CRC cells. Fourthly, SOX4 was upregulated in CRC tissues at the mRNA and protein 
levels. A significant negative correlation between miR-539 and SOX4 mRNA expression levels was also observed in CRC tissues. Finally, rescue experiments indicated that upregulation of SOX4 partially restored the tumor suppressive effects of miR-539, by suppressing the proliferation and invasion of CRC cells. It is essential to identify miR-539 target genes in order to elucidate the functions of miR-539 in the initiation and progression of CRC.

SOX4, a member of the SOX family of transcription factors, serves essential functions during embryonic development and cell fate specification in virtually all cells, tissues, and organ systems (40-42). SOX4 is overexpressed in multiple types of human cancer, including gastric cancer (43), hepatocellular carcinoma (44), prostate cancer (45), osteosarcoma (46) and non-small cell lung cancer (47). Furthermore, multiple studies have demonstrated that SOX4 serves an oncogenic function in tumorigenesis and tumor development. For example, inhibition of SOX4 represses prostate cancer proliferation, migration and invasion, and promotes the apoptotic process and the epithelial-mesenchymal transition in vitro (45). In CRC, SOX4 was upregulated at the mRNA and protein level, and was significantly associated with recurrence (29). SOX4 knockdown also inhibited the proliferation and invasion of CRC cells $(29,30)$. Therefore, SOX4 may be a novel therapeutic target in CRC, due to its cancer-associated functions.

To conclude, the present study indicated that miR-539 may function as a novel tumor suppressor in CRC. Our data provide a novel insight into the underlying mechanisms responsible for the progression of CRC. Therefore, the miR-539/SOX4 axis should be further investigated as a promising treatment for patients with CRC.

\section{Acknowledgements}

The present study was supported by the Clinical Capability Construction Project for Liaoning Provincial Hospitals (grant no. LNCCC-D42-2015).

\section{References}

1. Siegel RL, Miller KD and Jemal A: Cancer statistics, 2016. CA Cancer J Clin 66: 7-30, 2016.

2. Ferlay J, Shin HR, Bray F, Forman D, Mathers C and Parkin DM: Estimates of worldwide burden of cancer in 2008: GLOBOCAN 2008. Int J Cancer 127: 2893-2917, 2010.

3. Abdelsatir AA, Husain NE, Hassan AT, Elmadhoun WM, Almobarak AO and Ahmed MH: Potential benefit of metformin as treatment for colon cancer: The evidence so far. Asian Pac J Cancer Prev 16: 8053-8058, 2015.

4. Yu H, Gao G, Jiang L, Guo L, Lin M, Jiao X, Jia W and Huang J: Decreased expression of miR-218 is associated with poor prognosis in patients with colorectal cancer. Int J Clin Exp Pathol 6 : 2904-2911, 2013.

5. Meyerhardt JA and Mayer RJ: Systemic therapy for colorectal cancer. N Engl J Med 352: 476-487, 2005.

6. Varol U, Yildiz I, Salman T, Karabulut B and Uslu R: Markers to predict the efficacy of bevacizumab in the treatment of metastatic colorectal cancer. Tumori 100: 370-376, 2014.

7. Konda B, Shum H and Rajdev L: Anti-angiogenic agents in metastatic colorectal cancer. World J Gastrointest Oncol 7: 71-86, 2015.

8. Chen PS, Su JL and Hung MC: Dysregulation of microRNAs in cancer. J Biomed Sci 19: 90, 2012.

9. Bartel DP: MicroRNAs: Genomics, biogenesis, mechanism, and function. Cell 116: 281-297, 2004.
10. Zhou L, Liang $X$, Zhang L, Yang L, Nagao N, Wu H, Liu C, Lin S, Cai G and Liu J: miR-27a-3p functions as an oncogene in gastric cancer by targeting BTG2. Oncotarget 7: 51943-51954, 2016.

11. Tagscherer KE, Fassl A, Sinkovic T, Richter J, Schecher S, Macher-Goeppinger S and Roth W: MicroRNA-210 induces apoptosis in colorectal cancer via induction of reactive oxygen. Cancer Cell Int 16: 42, 2016.

12. Cui F, Wang S, Lao I, Zhou C, Kong H, Bayaxi N, Li J, Chen Q, Zhu T and Zhu H: miR-375 inhibits the invasion and metastasis of colorectal cancer via targeting SP1 and regulating EMT-associated genes. Oncol Rep 36: 487-493, 2016.

13. Calin GA, Sevignani C, Dumitru CD, Hyslop T, Noch E, Yendamuri S, Shimizu M, Rattan S, Bullrich F, Negrini M and Croce CM: Human microRNA genes are frequently located at fragile sites and genomic regions involved in cancers. Proc Natl Acad Sci USA 101: 2999-3004, 2004.

14. Griffiths-Jones S, Grocock RJ, van Dongen S, Bateman A and Enright AJ: miRBase: microRNA sequences, targets and gene nomenclature. Nucleic Acids Res 34 (Database Issue): D140-D144, 2006.

15. Dong F, Xu T, Shen Y, Zhong S, Chen S, Ding Q and Shen Z: Dysregulation of miRNAs in bladder cancer: Altered expression with aberrant biogenesis procedure. Oncotarget 8: 27547-27568, 2017.

16. Zhou L, Xu Z, Ren X, Chen K and Xin S: MicroRNA-124 (miR-124) inhibits cell proliferation, metastasis and invasion in colorectal cancer by downregulating Rho-associated protein kinase 1 (ROCK1). Cell Physiol Biochem 38: 1785-1795, 2016.

17. Jiang $\mathrm{H}, \mathrm{Ju} \mathrm{H}$, Zhang L, Lu H and Jie K: microRNA-577 suppresses tumor growth and enhances chemosensitivity in colorectal cancer. J Biochem Mol Toxicol 31: e21888, 2017.

18. Shenouda SK and Alahari SK: MicroRNA function in cancer: Oncogene or a tumor suppressor? Cancer Metastasis Rev 28: 369-378, 2009.

19. Porkka KP,Pfeiffer MJ, Waltering KK, Vessella RL, Tammela TL and Visakorpi T: MicroRNA expression profiling in prostate cancer. Cancer Res 67: 6130-6135, 2007.

20. Zhang H, Li S, Yang X, Qiao B, Zhang Z and Xu Y: miR-539 inhibits prostate cancer progression by directly targeting SPAG5. J Exp Clin Cancer Res 35: 60, 2016.

21. Lv LY, Wang YZ, Zhang Q, Zang HR and Wang XJ: miR-539 induces cell cycle arrest in nasopharyngeal carcinoma by targeting cyclin-dependent kinase 4. Cell Biochem Funct 33: $534-540,2015$.

22. Jin H and Wang W: MicroRNA-539 suppresses osteosarcoma cell invasion and migration in vitro and targeting Matrix metallopeptidase-8. Int J Clin Exp Pathol 8: 8075-8082, 2015.

23. Livak KJ and Schmittgen TD: Analysis of relative gene expression data using real-time quantitative PCR and the 2(-Delta Delta C(T)) method. Methods 25: 402-408, 2001.

24. Lewis BP, Burge CB and Bartel DP: Conserved seed pairing, often flanked by adenosines, indicates that thousands of human genes are microRNA targets. Cell 120: 15-20, 2005.

25. Kozomara A and Griffiths-Jones S: miRBase: Annotating high confidence microRNAs using deep sequencing data. Nucleic Acids Res 42 (Database Issue): D68-D73, 2014.

26. Kozomara A and Griffiths-Jones S: miRBase: Integrating microRNA annotation and deep-sequencing data. Nucleic Acids Res 39 (Database Issue): D152-D157, 2011.

27. Griffiths-Jones S, Saini HK, van Dongen S and Enright AJ: miRBase: Tools for microRNA genomics. Nucleic Acids Res 36 (Database Issue): D154-D158, 2008.

28. Shia J, Klimstra DS, Bagci P, Basturk O and Adsay NV: TNM staging of colorectal carcinoma: Issues and caveats. Semin Diagn Pathol 29: 142-153, 2012.

29. Wang B, Li Y, Tan F and Xiao Z: Increased expression of SOX4 is associated with colorectal cancer progression. Tumour Biol 37: 9131-9137, 2016.

30. Andersen CL, Christensen LL, Thorsen K, Schepeler T, Sørensen FB, Verspaget HW, Simon R, Kruhøffer M, Aaltonen LA, Laurberg S and Ørntoft TF: Dysregulation of the transcription factors SOX4, CBFB and SMARCC1 correlates with outcome of colorectal cancer. Br J Cancer 100: 511-523, 2009.

31. Guda K, Veigl ML, Varadan V, Nosrati A, Ravi L, Lutterbaugh J, Beard L, Willson JK, Sedwick WD, Wang ZJ, et al: Novel recurrently mutated genes in African American colon cancers. Proc Natl Acad Sci USA 112: 1149-1154, 2015. 
32. Vaiopoulos AG, Athanasoula $\mathrm{KCh}$ and Papavassiliou AG: Epigenetic modifications in colorectal cancer: Molecular insights and therapeutic challenges. Biochim Biophys Acta 1842: 971-980, 2014

33. Bardhan K and Liu K: Epigenetics and colorectal cancer pathogenesis. Cancers (Basel) 5: 676-713, 2013.

34. Iorio MV and Croce CM: MicroRNA dysregulation in cancer: Diagnostics, monitoring and therapeutics. A comprehensive review. EMBO Mol Med 4: 143-159, 2012.

35. Qu S, Yao Y, Shang C, Xue Y, Ma J, Li Z and Liu Y: MicroRNA-330 is an oncogenic factor in glioblastoma cells by regulating SH3GL2 gene. PLoS One 7: e46010, 2012.

36. Li G, Yang F, Xu H, Yue Z, Fang X and Liu J: MicroRNA-708 is downregulated in hepatocellular carcinoma and suppresses tumor invasion and migration. Biomed Pharmacother 73: $154-159,2015$

37. Hu H, Zhang Y, Cai XH, Huang JF and Cai L: Changes in microRNA expression in the MG-63 osteosarcoma cell line compared with osteoblasts. Oncol Lett 4: 1037-1042, 2012.

38. Mirghasemi A, Taheriazam A, Karbasy SH, Torkaman A, Shakeri M, Yahaghi E and Mokarizadeh A: Down-regulation of miR-133a and miR-539 are associated with unfavorable prognosis in patients suffering from osteosarcoma. Cancer Cell Int 15: 86, 2015

39. Gu L and Sun W: miR-539 inhibits thyroid cancer cell migration and invasion by directly targeting CARMA1. Biochem Biophys Res Commun 464: 1128-1133, 2015.
40. Schepers GE, Teasdale RD and Koopman P: Twenty pairs of sox: Extent, homology, and nomenclature of the mouse and human sox transcription factor gene families. Dev Cell 3: 167-170, 2002.

41. Wegner M: From head to toes: The multiple facets of sox proteins. Nucleic Acids Res 27: 1409-1420, 1999.

42. Cheung M, Abu-Elmagd M, Clevers H and Scotting PJ: Roles of Sox4 in central nervous system development. Brain Res Mol Brain Res 79: 180-191, 2000.

43. Fang CL, Hseu YC, Lin YF, Hung ST, Tai C, Uen YH and Lin KY: Clinical and prognostic association of transcription factor SOX4 in gastric cancer. PLoS One 7: e52804, 2012.

44. Zheng JH, Jian ZX, Jin HS, Chen SC and Wang GY: Expression of SOX4 gene and early recurrence of hepatocellular carcinoma: Their relationship and the clinical significance. Nan Fang Yi Ke Da Xue Xue Bao 30: 818-819, 2010 (In Chinese).

45. Wang L, Zhang J, Yang X, Chang YW, Qi M, Zhou Z, Zhang J and Han B: SOX4 is associated with poor prognosis in prostate cancer and promotes epithelial-mesenchymal transition in vitro. Prostate Cancer Prostatic Dis 16: 301-307, 2013.

46. Bao ZQ, Zhang CC, Xiao YZ, Zhou JS, Tao YS and Chai DM Over-expression of Sox 4 and $\beta$-catenin is associated with a less favorable prognosis of osteosarcoma. J Huazhong Univ Sci Technolog Med Sci 36: 193-199, 2016.

47. Wang D, Hao T, Pan Y, Qian X and Zhou D: Increased expression of SOX4 is a biomarker for malignant status and poor prognosis in patients with non-small cell lung cancer. Mol Cell Biochem 402: 75-82, 2015. 